\title{
OPEN Retraction Note: Theoretical Limits of Energy Density in Silicon-Carbon Composite Anode Based Lithium Ion Batteries
}

\author{
Ranjan Dash ${ }^{1} \&$ Sreekanth Pannala ${ }^{2}$ \\ Retraction of: Scientific Reports https://doi.org/10.1038/srep27449, published online 17 June 2016 \\ The editors retract this article.
}

Equation (3) in the article, describing the porosity of the anode, contains a normalization error. Instead of using the volume fractions of silicon and graphite in the calculation of the anode porosity, their weight fractions are used. When the relationship between the volumetric capacity of the anode and the silicon amount (Figure 2 in the article) is correctly calculated, this relationship does no longer have a maximum: the volumetric capacity continuously increases with the increasing silicon amount in the anode. The relationships between volumetric and gravimetric capacities of electrodes made with different materials, shown in Figure 3, no longer hold. Since the conclusions of the article are based on the presence of the threshold value of Si amount in the electrode, which is incorrect, the editors retract the article.

The authors disagree with the retraction.

(i) Open Access This article is licensed under a Creative Commons Attribution 4.0 International License, which permits use, sharing, adaptation, distribution and reproduction in any medium or format, as long as you give appropriate credit to the original author(s) and the source, provide a link to the Creative Commons license, and indicate if changes were made. The images or other third party material in this article are included in the article's Creative Commons license, unless indicated otherwise in a credit line to the material. If material is not included in the article's Creative Commons license and your intended use is not permitted by statutory regulation or exceeds the permitted use, you will need to obtain permission directly from the copyright holder. To view a copy of this license, visit http://creativecommons.org/licenses/by/4.0/.

(C) The Publisher 2019 